\title{
One-step Construction of Aminosquaraine Backbone
}

\author{
Hanze Ying ${ }^{1}$ and Jianjun Cheng ${ }^{1 *}$ \\ ${ }^{1}$ Department of Materials Science and Engineering, University of Illinois at Urbana- \\ Champaign, 1304 W. Green Street, Urbana, IL, 61801, USA
}

*Corresponding authors: jianjunc@illinois.edu

(C) 2016. This manuscript version is made available under the Elsevier user license http://www.elsevier.com/open-access/userlicense/1.0/ 


\begin{abstract}
:
One-step construction of the amino-substituted squaraine dye backbone was discovered unexpectedly in an amidation reaction. Under the catalysis of Mukaiyama's reagent, (4dimethylamino)phenylacetic acid and bulky secondary amine 2,2,6,6-tetramethylpiperidine give the reduced form of aminosquaraine instead of amide as the major product. The reduced form of aminosquaraine can be oxidized to a dark-colored conjugated aminosquaraine within seconds. The method provides a novel and facile way to functionalize the four-membered core of squaraine dye.
\end{abstract}

\title{
Key words:
}

Squaraine, aminosquaraine, one-step, amidation, oxidation, dye functionalization 


\section{Introduction}

Squaraine dyes are a class of conjugated organic dyes with strong absorption in visible to nearinfrared region (low band-gap), which features a four-membered aromatic ring structure as the core (see one example in Scheme 1a). Over the past few decades, squaraine dyes have been developed for many different applications ${ }^{1,2}$, including sensors ${ }^{3,4}$, organic electronics ${ }^{5-7}$, and photo dynamic therapies (PDT) ${ }^{8,9}$. Squaraine dyes are usually synthesized through condensation reaction of electron-rich arenes and squaric acid (Scheme $1 \mathrm{~b})^{1}$. Structure tuning of squaraine dyes are mostly focused on interchanging and modifying the arenes, while the functionalization of the squaric core (Scheme 1a) is challenging ${ }^{1}$. It has been reported that the squaric core can be modified with a substituted methylene group via a semisquarate intermediate ${ }^{10}$. The squaric core can also be modified by amino group through post-modification using sequential reduction-substitutionoxidation reactions (Scheme $1 \mathrm{~b})^{11}$. However, both routes involve tedious multi-step syntheses. Herein, we report a new method to synthesize amino substituted squaraine (also named as aminosquaraine), which is discovered unexpectedly in a simple amidation reaction (Scheme 1b), and takes only one step to construct the aminosquaraine backbone.

\section{Results and discussions}

2.1. Unexpected synthesis of aminosquaraine backbone from amidation reaction.

(4-Dimethylamino)phenylacetic acid (1, 1.0 equiv.) and bulky secondary amine 2,2,6,6tetramethylpiperidine $(\mathbf{2}, 3.0$ equiv.) were mixed with Mukaiyama's reagent $(\mathbf{3}, 1.5$ equiv.) as the carboxylic acid activation reagent. After the mixture was vigorously stirred for $12 \mathrm{~h}$, one new major product was observed using thin layer chromatography (TLC). Purification of the 
compound via column chromatography, and ${ }^{1} \mathrm{H}$ NMR characterization showed that the structure did not match the structure of expected amide product 4 (Figure 1a). Comparing with simulated ${ }^{1} \mathrm{H}$ NMR spectrum of 4, each peak for protons in phenyl ring and methyl groups in aniline and bulky amine groups splits into two, which manifests that the compound is asymmetric (Figure $1 \mathrm{~b}$ \& S2). Based on integrals of peaks, the compound contains two aniline and one bulky amine structures (or their integer multiples). Integrating the above information and the molecular weight obtained from mass spectrometry (MS), we identified the structure as compound $\mathbf{5}$ (Figure 1b). Compound $\mathbf{5}$ contains characteristic four membered ring core structure, which is the reduced form of 1-(2,2,6,6-tetramethylpiperidinyl) substituted aniline based squaraine dye.

2.2. Proposed mechanism for the formation of reduced form of aminosquaraine dye.

Scheme 2a illustrates the proposed mechanism for the formation of reduced aminosquaraine 5. The carboxylic acid $\mathbf{1}$ is first activated by Mukaiyama's reagent, followed by substitution with bulky amine 2 giving amide 4, the targeted product. Because of the presence of basic amines in the reaction and the stability of benzyl anions, amide $\mathbf{4}$ likely undergoes deprotonation followed by Claisen condensation with another molecule of activated carboxylic ester to form ketone $\mathbf{8}$. Ketone $\mathbf{8}$ can then undergo intramolecular Aldol condensation, giving the final product $\mathbf{5}$.

Electron-rich carboxylic acid and bulky amine are required for the reaction to proceed. When $\mathbf{1}$ was changed to more electron deficient 1', or $\mathbf{2}$ was changed to less bulky primary amine 2' while reaction conditions and reactant molar ratios were kept the same, no aminosquaraine dye was detected. Instead, amides were obtained in high yield (Scheme S2 S5, Figure S3 S7). It is presumably because: i) For electron deficient amide 4', the benzylic carbanion is less nucleophilic and tends to form ketene by elimination of bulky amine group (previously reported as dynamic 
amide) ${ }^{12}$, making it less likely for Claisen condensation to occur; ii) Typical ring-closing intramolecular Aldol condensations occur between carbanions and electrophilic carbonyl compounds (aldehydes/ketones). Normally, the more electron-rich amides do not participate in this reaction. However, the bulky amide does not completely adopt the typical amide structure. To avoid the steric hindrance, the $\mathrm{C}-\mathrm{N}$ bond has lower energy barrier to rotate, which partially breaks the electron delocalization amide bond, making the amide more like a 'ketone' for Aldol reaction ${ }^{12}$.

\subsection{Synthesis of conjugated aminosquaraine dye.}

As a reduced form of dye, compound $\mathbf{5}$ could be easily oxidized to give fully conjugated aminosquaraine dye. Interestingly, it was observed that the spot of $\mathbf{5}$ on the TLC plate gradually turned green after being exposed to air for several minutes. To further understand the oxidation process of 5, DDQ (6, 2,3-dichloro-5,6-dicyano-1,4-benzoquinone), a widely used organic oxidant for dehydrogenation/aromatization reactions, was used to treat $\mathbf{5}$. When mixing 5 and $\mathbf{6}$ in 1:1 molar ratio (Figure 2a), we observed immediate color change from light yellow to dark blue (Figure 2c), and the reaction finished within minutes. ${ }^{1} \mathrm{H}$ NMR illustrates that all peaks for 5 moved to downfield, and the 'split' peak pairs merged into singlet peaks (Figure 2b). It corresponds well to the fact that the asymmetric $\mathbf{5}$ becomes symmetric and more electron deficient after being oxidized to 7. Also, the peaks became much broader, possibly due to the electrostatic and $\pi-\pi$ interactions between cationic 7 and anionic reduced form of $\mathbf{6}$. The molecular weight measured by MS showed the reduction of molecular weight by 2 , which also confirmed the dehydrogenation process. Titration of $\mathbf{6}$ to $\mathbf{5}$ demonstrated the oxidation reaction stoichiometry to be 1:1 (Figure S9). 
We then characterized the UV-Vis absorption of squaraine dye before and after oxidation. As shown in Figure 2c, 5 and $\mathbf{6}$ only showed absorption signals below $500 \mathrm{~nm}$. After mixing, a very intense absorption signal appeared in long wavelength range peaked at $649 \mathrm{~nm}$, which confirmed the extension of conjugation from 5 to 7. We noticed that the H-transfer in this oxidation process has perfect geometric match. As shown in Figure 2a, 5 and 6 co-facially approach each other through a donor-acceptor interaction. When one of the oxygen atoms of $\mathbf{6}$ abstracts the $\mathrm{H}^{-}$from the methine of $\mathbf{5}$, the other oxygen atom of $\mathbf{6}$ builds negative charge through electron transfer, which is at the correct position for electrostatic interaction with the newly formed positive charge of nitrogen in 5. This synergistic process lowers the transition state energy, and explains the fast kinetics of this oxidation reaction.

\section{Concolusion}

In conclusion, we report that the amidation reaction between electron-rich phenylacetic acid and bulky secondary amine unexpectedly leads to the synthesis of reduced amino-substituted squaraine dye $\mathbf{5}$ in one step, which avoids the conventional multi-step synthesis in previous reports. We found that the electron-rich carboxylic acid and amine with bulky substituents are required for the reaction to proceed. The reductive aminosquaraine can be oxidized by organic oxidant DDQ within minutes, giving cationic aminosquaraine with extended conjugated structure and intensive absorption in long wavelength range. Studies to further explore this unique reaction are underway, including the tests of different amine and carboxylic acid substrates. The photophysical properties change after oxidation potentiates the use of the compound as an indicator of oxidative species (e.g., reactive oxygen species (ROS)). Studies are also underway to explore the absorbance/fluorescence response and selectivity of reduced aminosquaraine dye to various ROS. 
Overall, with the ease of synthesis and feasibility of core-functionalization, bioconjugation, and tuning of photophysical properties, the amino-substituted squaraine dyes may become new candidates for the design of new biological and electronic materials.

This work is supported by United States National Science Foundation (CHENSF CHE 15-08710).

\section{Appendix A. Supplementary data}

Supplementary data related to this article can be found at $\mathrm{xxx}$ 


\section{References:}

[1] L. Hu, Z. Q. Yan and H. Y. Xu, RSC Adv., 2013, 3, 7667.

[2] L. Beverina and P. Salice, Eur. J. Org. Chem., 2010, 1207.

[3] P. Anees, S. Sreejith and A. Ajayaghosh, J. Am. Chem. Soc., 2014, 136, 13233.

[4] D. Yao, Z. Lin, and J. Wu, ACS Appl. Mater. Interfaces, 2016, 8, 5847

[5] G. Chen, H. Sasabe, T. Igarashi, Z. R. Hong and J. Kido, J. Mater. Chem. A, 2015, 3, 14517.

[6] M. Gsanger, E. Kirchner, M. Stolte, C. Burschka, V. Stepanenko, J. Pflaum and F. Wurthner, J. Am. Chem. Soc., 2014, 136, 2351.

[7] J. S. Huang, T. Goh, X. K. Li, M. Y. Sfeir, E. A. Bielinski, S. Tomasulo, M. L. Lee, N. Hazari and A. D. Taylor, Nat. Photonics, 2013, 7, 480.

[8] J. M. Baumes, J. J. Gassensmith, J. Giblin, J. J. Lee, A. G. White, W. J. Culligan, W. M. Leevy, M. Kuno and B. D. Smith, Nat. Chem., 2010, 2, 1025.

[9] R. R. Avirah, D. T. Jayaram, N. Adarsh and D. Ramaiah, Org. Biomol. Chem., 2012, 10, 911.

[10] A. L. Tatarets, I. A. Fedyunyaeva, E. Terpetschnig and L. D. Patsenker, Dyes Pigments, 2005, 64, 125.

[11] J. Griffiths and S. Park, Tetrahedron Lett., 2002, 43, 7669.

[12] M. Hutchby, C. E. Houlden, M. F. Haddow, S. N. Tyler, G. C. Lloyd-Jones and K. I. BookerMilburn, Angew. Chem. Int. Ed., 2012, 51, 548. 
a<smiles>CN(C)c1ccc(C2=C([O-])C(=C3C=CC(=[N+](C)C)C=C3)C2=O)cc1</smiles>

Core substituted aniline squaraine dye
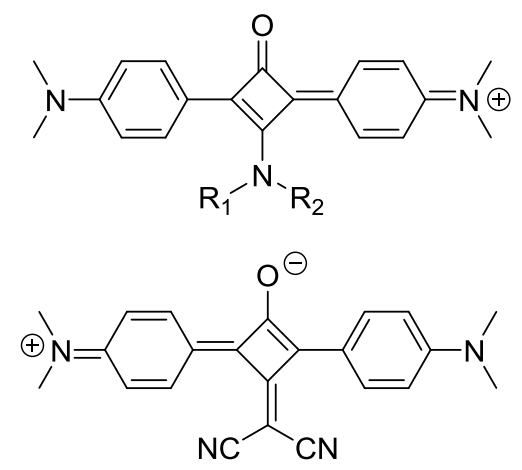

b Conventional method:<smiles>[Z]N(C)c1cc[c+][cH+]c1=c1c(=O)c(=C2C=CC(=[N+](C)C)C=C2)c1=O</smiles>

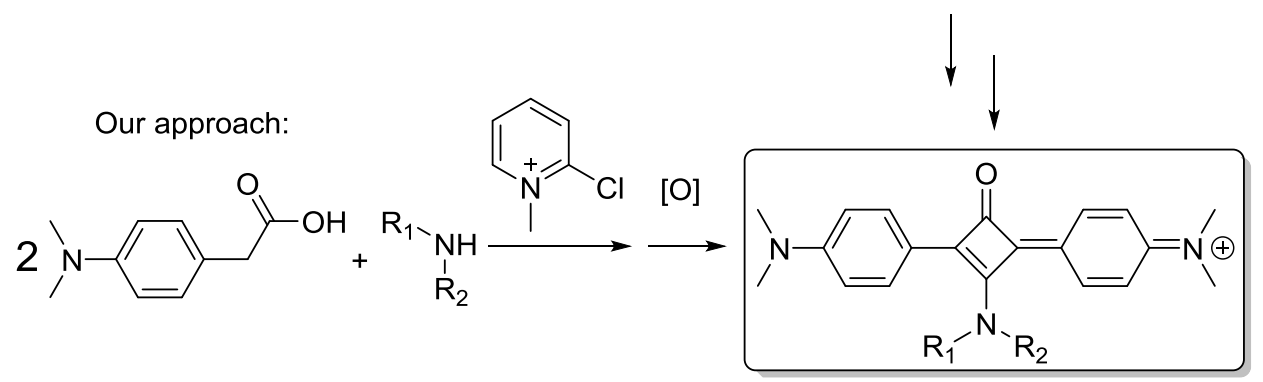

Scheme 1. Squaraine dye derivatives: (a) Structures of squaraine and core-substituted squaraine dyes. (b) Conventional and our new approaches to synthesize amino-substituted squaraine 

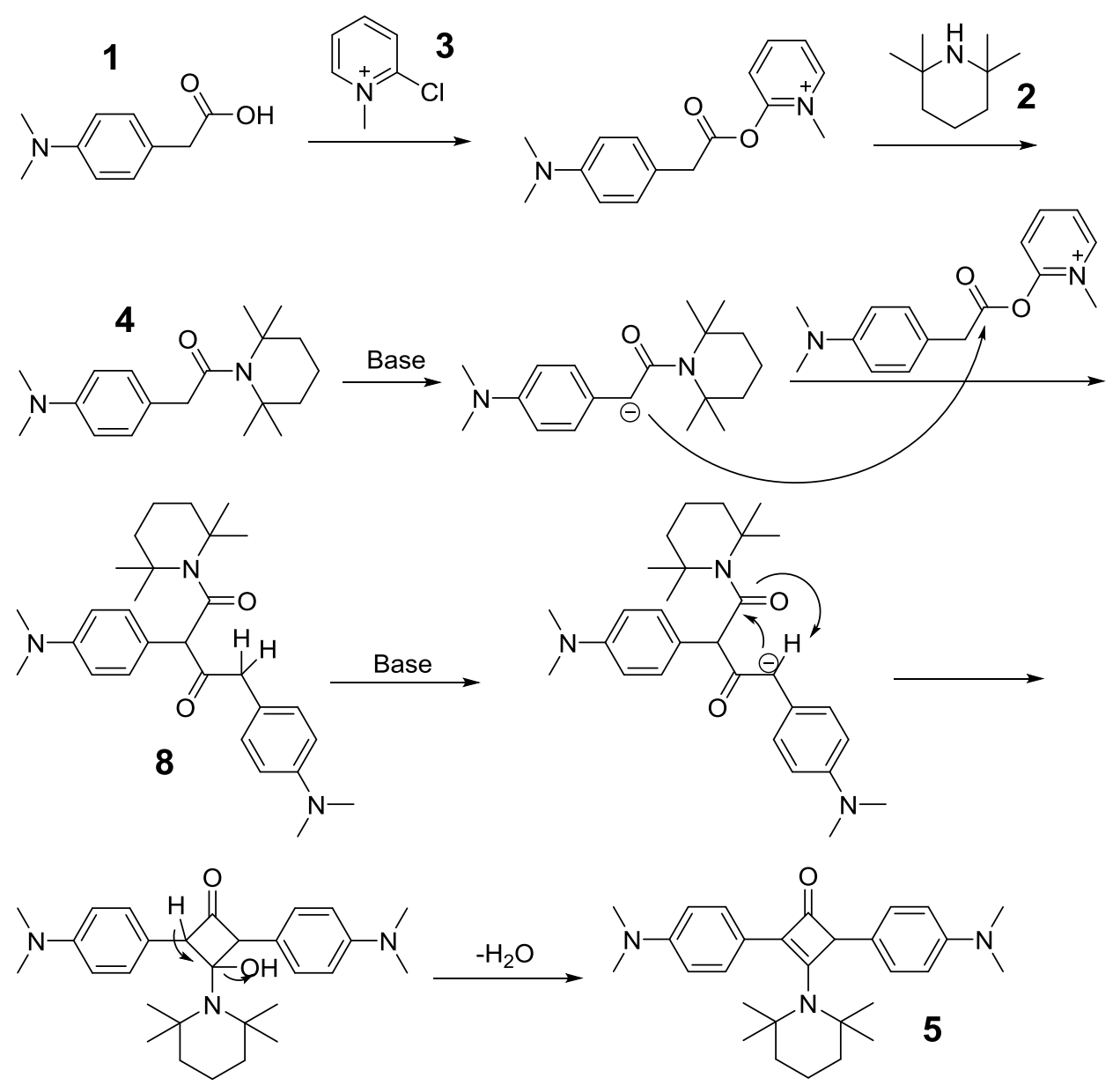

Scheme 2. Proposed mechanism for the synthesis of reduced form of aminosquaraine 5. 


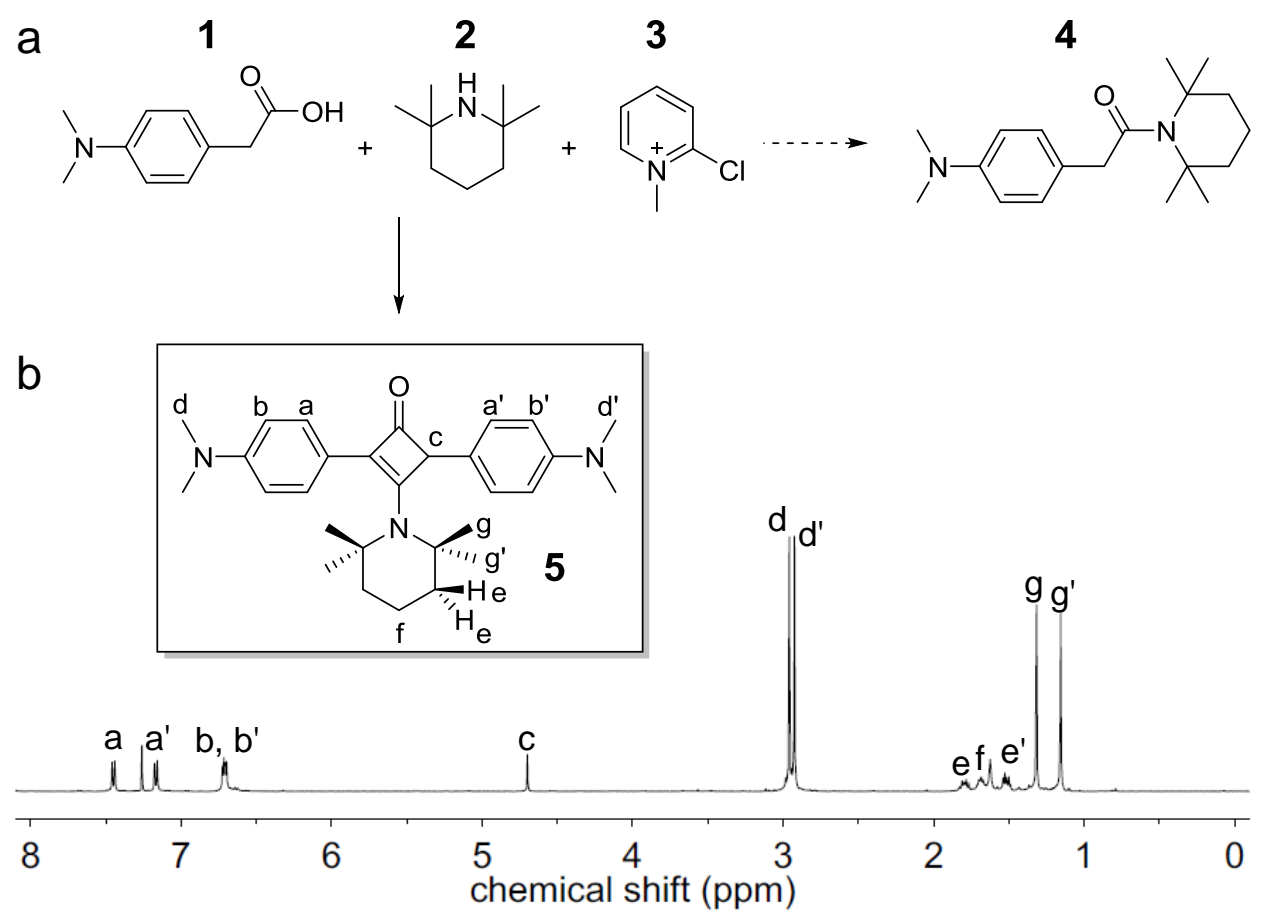

Figure 1. Amidation reaction gives unexpected product: (a) Amidation reaction of $\mathbf{1}$ and $\mathbf{2}$ gives reductive squaraine derivative 5 instead of expected amide 4 as the major product; (b) ${ }^{1} \mathrm{H}$ NMR spectrum of $\mathbf{5}$ (peaks were assigned to corresponding protons). 
a
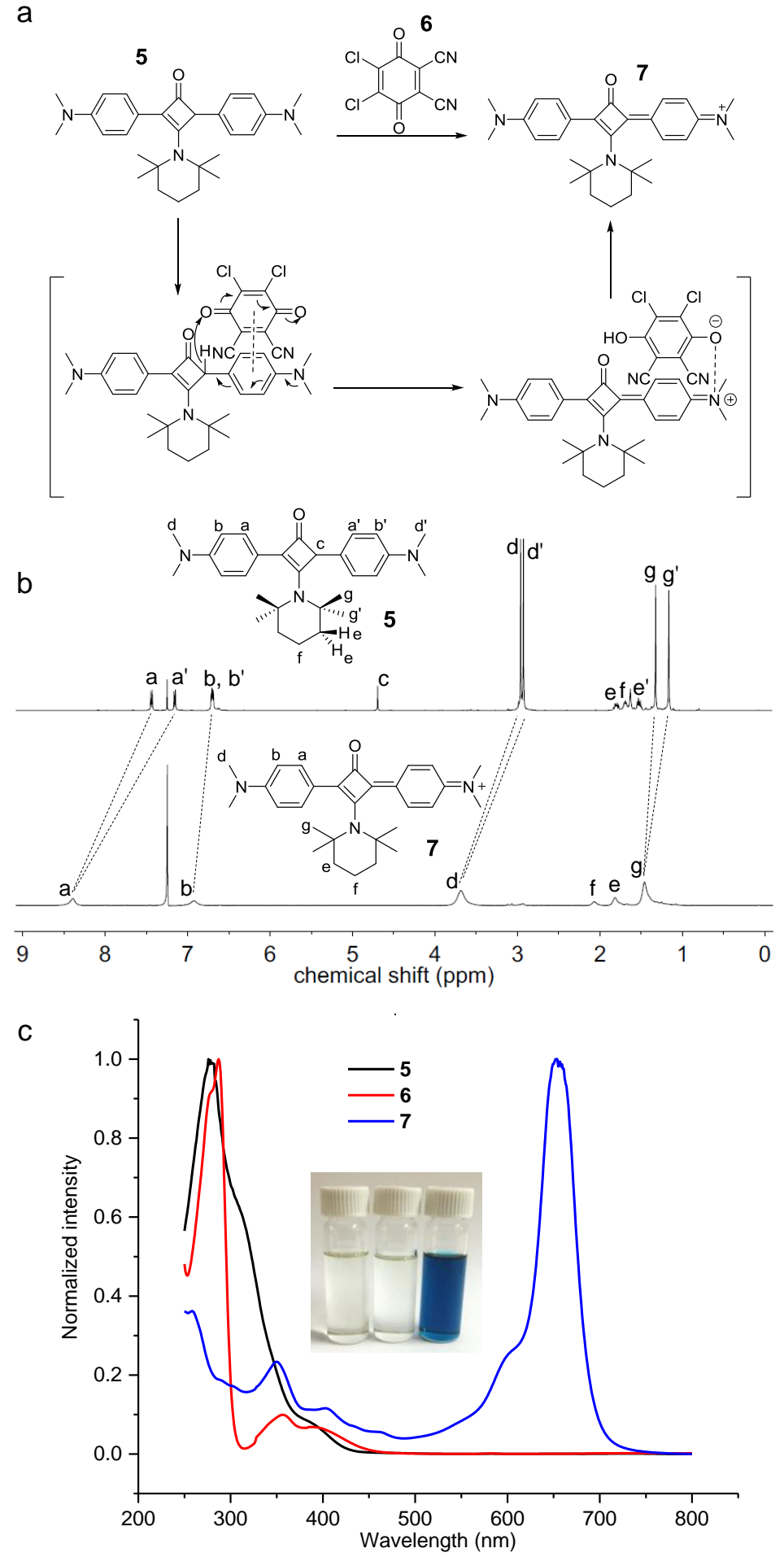

Figure 2. Oxidation of 5 by DDQ: (a) Scheme showing oxidation of 5 by DDQ with the proposed synergistic hydride transfer mechanism; (b) Comparison of ${ }^{1} \mathrm{H}$ NMR spectra of 5 (asymmetric reductive form) and 7 (symmetric oxidative form); (c) UV-Vis absorption spectra of 5, 6, and 7; Inset: images of solutions of 5, 6, and $\mathbf{7}$ showing significant color change before and after mixing of 5 and $\mathbf{6}$ (all solutions were characterized in the concentration of $10^{-4} \mathrm{M}$ ). 


\title{
Supporting Information
}

One-step Construction of Aminosquaraine Backbone

\author{
Hanze Ying and Jianjun Cheng*
}

Department of Materials Science and Engineering, University of Illinois at Urbana-Champaign, 1304 W. Green Street, Urbana, IL, 61801, USA

*Corresponding author: jianjunc@illinois.edu 


\section{General}

Materials. Anhydrous dichloromethane (DCM) was dried by a column packed with alumina. All deuterated solvents were purchased from Cambridge Isotope Laboratories, Inc. and used as received. All other chemicals were purchased from Sigma-Aldrich (St. Louis, MO, USA) and used as received unless otherwise specified.

Instrumentation. NMR spectra were recorded on Varian U500 (500 MHz) spectrometer. Mass spectra were recorded on Waters Q-TOF Ultima ESI. UV-Vis spectra were recorded on Perkin Elmer lambda 25.

Scheme S1. Synthesis of aminosquaraine dye 5

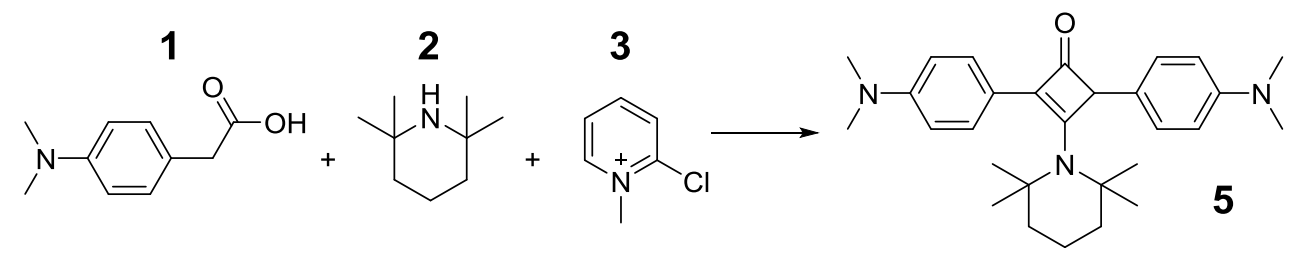

Synthesis of aminosquaraine dye 5. 4-(Dimethylamino)phenylacetic acid (1, $1.00 \mathrm{~g}, 5.59 \mathrm{mmol})$ was dissolved in $100 \mathrm{~mL}$ anhydrous DCM, followed by the addition of 2-chloro-1methylpyridinium iodide $(3,2.14 \mathrm{~g}, 8.38 \mathrm{mmol})$. After $15 \mathrm{~min}$, 2,2,6,6-tetramethylpiperidine (2, $2.36 \mathrm{~g}, 16.7 \mathrm{mmol}$ ) was added dropwise. Then the mixture was allowed to react at room temperature for $24 \mathrm{~h}$. After that, the mixture was diluted with DCM (100 mL), and washed with saturated $\mathrm{NaHCO}_{3}$ solution $(3 \times 50 \mathrm{~mL})$ and brine $(3 \times 50 \mathrm{~mL})$. The organic phase was dried by anhydrous $\mathrm{Na}_{2} \mathrm{SO}_{4}$. After the solvent was removed by vacuum, the residue was purified by column chromatography (hexane/EtOAc $=5: 1$ to $2: 1, \mathrm{v} / \mathrm{v})$ to give brown solid as the final product $(160$ mg, yield 12\%). ${ }^{1} \mathrm{H}$ NMR (500 MHz, $\left.\mathrm{CDCl}_{3}\right): \delta 7.45(\mathrm{~d}, J=8.5 \mathrm{~Hz}, 2 \mathrm{H}, \mathrm{Ph}-\underline{\mathrm{H}}), 7.17(\mathrm{~d}, J=8.5$

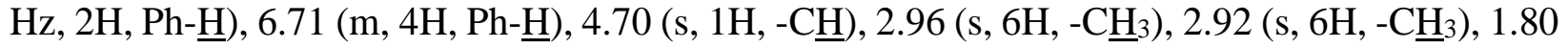
(m, 2H, $\left.-\underline{\mathrm{C}}_{2}\right), 1.68\left(\mathrm{~m}, 2 \mathrm{H},-\underline{\mathrm{CH}}_{2}\right), 1.51\left(\mathrm{~m}, 2 \mathrm{H},-\mathrm{C}_{2}\right), 1.32\left(\mathrm{~s}, 6 \mathrm{H},-\underline{\mathrm{C}}_{3}\right), 1.16\left(\mathrm{~s}, 6 \mathrm{H},-\underline{\mathrm{H}}_{3}\right)$, ${ }^{13} \mathrm{C}$ NMR (125 MHz, $\left.\mathrm{CDCl}_{3}\right), \delta 189.9,169.4,150.2,150.0,132.8,130.9,129.3,125.5,121.0$, 113.1, 112.4, 70.7, 58.2, 41.0, 40.7, 38.3, 32.5, 27.4, 15.7 (Figure S1). ESI-MS (low resolution, positive mode): calculated for $\mathrm{C}_{29} \mathrm{H}_{40} \mathrm{~N}_{3} \mathrm{O}, \mathrm{m} / \mathrm{z}, 446.3[\mathrm{M}+\mathrm{H}]^{+}$; found $446.2[\mathrm{M}+\mathrm{H}]^{+}$.

Scheme S2. Synthesis of amide 4' 


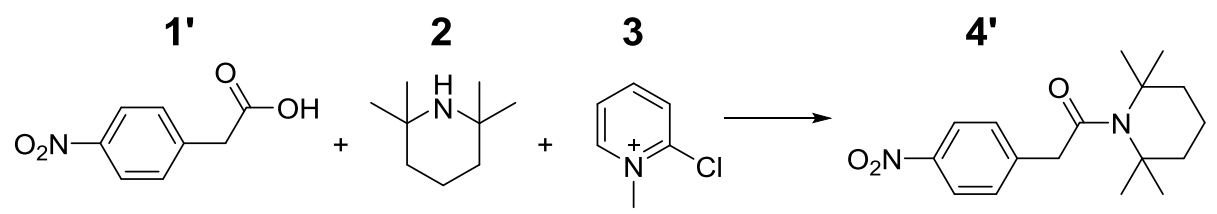

Synthesis of 4'. 4-Nitrophenylacetic acid (1', $0.200 \mathrm{~g}, 1.10 \mathrm{mmol})$ was dissolved in $20 \mathrm{~mL}$ anhydrous DCM, followed by the addition of 2-chloro-1-methylpyridinium iodide $(3,0.423 \mathrm{~g}, 1.66$ mmol). After $15 \mathrm{~min}, 2$,2,6,6-tetramethylpiperidine (2, $0.467 \mathrm{~g}, 3.31 \mathrm{mmol})$ was added dropwise. Then the mixture was allowed to react at room temperature for $24 \mathrm{~h}$. After that, the mixture was diluted with DCM $(100 \mathrm{~mL})$, and washed with saturated $\mathrm{NaHCO}_{3}$ solution $(3 \times 50 \mathrm{~mL})$ and brine $(3 \times 50 \mathrm{~mL})$. The organic phase was dried by anhydrous $\mathrm{Na}_{2} \mathrm{SO}_{4}$. After the solvent was removed by vacuum, the residue was purified by column chromatography (hexane/EtOAc $=2: 1 \mathrm{v} / \mathrm{v}$ ) to give grey solid as the final product $(120 \mathrm{mg}$, yield $36 \%) .{ }^{1} \mathrm{H} \mathrm{NMR}\left(500 \mathrm{MHz}, \mathrm{CDCl}_{3}\right): \delta 8.16(\mathrm{~d}, J=$ $8.5 \mathrm{~Hz}, 2 \mathrm{H}, \mathrm{Ph}-\underline{\mathrm{H}}), 7.47$ (d, J = 8.5 Hz, 2H, Ph- $\underline{\mathrm{H}}), 3.81$ (s, 2H, - $\left.\underline{\mathrm{H}}_{2}\right), 2.92$ (s, 6H, - $\left.\underline{\mathrm{H}}_{3}\right), 1.79$ (m, $\left.6 \mathrm{H},-\underline{\mathrm{C}}_{2}\right), 1.47$ (s, 12H, $\left.-\mathrm{C}_{3}\right),{ }^{13} \mathrm{C} \mathrm{NMR}\left(125 \mathrm{MHz}, \mathrm{CDCl}_{3}\right), \delta 173.8,146.9,145.0,130.4,123.7$, 56.5, 46.4, 36.7, 30.5, 14.6 (Figure S3). ESI-MS (low resolution, positive mode): calculated for $\mathrm{C}_{17} \mathrm{H}_{25} \mathrm{~N}_{2} \mathrm{O}_{3}, \mathrm{~m} / \mathrm{z}, 305.2[\mathrm{M}+\mathrm{H}]^{+}$; found $305.2[\mathrm{M}+\mathrm{H}]^{+}$.

Scheme S3. Synthesis of amide 4,"

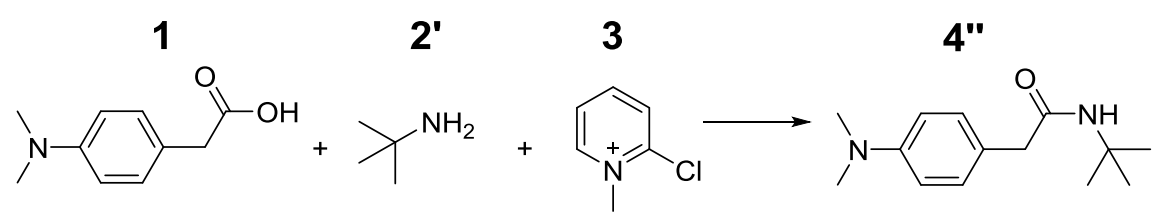

Synthesis of 4', 4-(Dimethylamino)phenylacetic acid (1,0.200 g, $1.12 \mathrm{mmol})$ was dissolved in $20 \mathrm{~mL}$ anhydrous DCM, followed by the addition of 2-chloro-1-methylpyridinium iodide (3, 0.428 g, $1.68 \mathrm{mmol}$ ). After $15 \mathrm{~min}, t$-butylamine (2', $0.241 \mathrm{~g}, 3.30 \mathrm{mmol}$ ) was added dropwise. Then the mixture was allowed to react at room temperature for $24 \mathrm{~h}$. After that, the mixture was diluted with DCM $(100 \mathrm{~mL})$, and washed with saturated $\mathrm{NaHCO}_{3}$ solution $(3 \times 50 \mathrm{~mL})$ and brine $(3 \times 50 \mathrm{~mL})$. The organic phase was dried by anhydrous $\mathrm{Na}_{2} \mathrm{SO}_{4}$. After the solvent was removed by vacuum, the residue was purified by column chromatography (hexane/EtOAc $=2: 1 \mathrm{v} / \mathrm{v}$ ) to give grey solid as the final product (126 mg, yield 47\%). $\left.{ }^{1} \mathrm{H} \mathrm{NMR} \mathrm{(500} \mathrm{MHz,} \mathrm{CDCl}_{3}\right), \delta 7.08(\mathrm{~d}, J=8.5 \mathrm{~Hz}, 2 \mathrm{H}$,

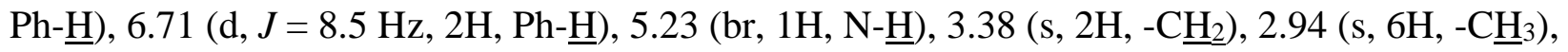
$1.26\left(\mathrm{~s}, 12 \mathrm{H},-\mathrm{C}_{3}\right),{ }^{13} \mathrm{C} \mathrm{NMR}\left(125 \mathrm{MHz}, \mathrm{CDCl}_{3}\right), \delta$ 171.6, 149.9, 130.3, 123.3, 113.3, 51.3, 44.2, 
40.9, 29.0 (Figure S4). ESI-MS (low resolution, positive mode): calculated for $\mathrm{C}_{14} \mathrm{H}_{23} \mathrm{~N}_{2} \mathrm{O}, \mathrm{m} / \mathrm{z}$, $235.2[\mathrm{M}+\mathrm{H}]^{+}$; found $235.2[\mathrm{M}+\mathrm{H}]^{+}$.

Scheme S4. Attempt to synthesize squaraine dye starting from 4'
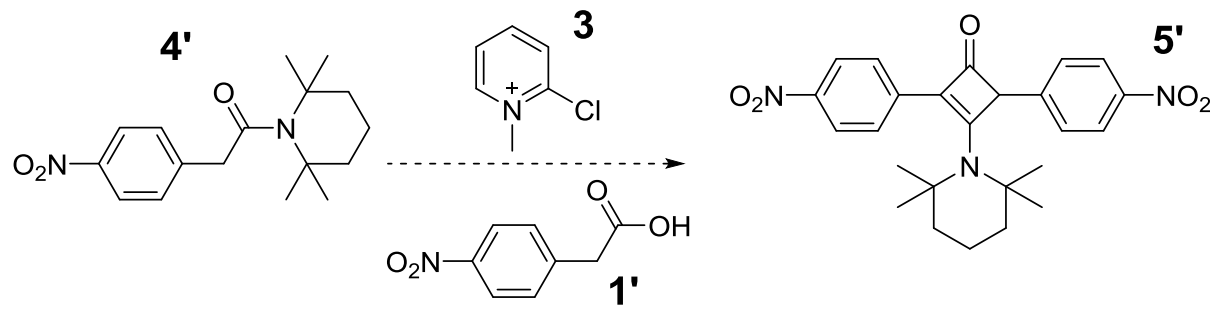

Attempt to synthesize squaraine dye 5' starting from 4': Compound 4' (50 mg, $0.164 \mathrm{mmol}$ ), 4-nitrophenylacetic acid (1', $30 \mathrm{mg}, 0.164 \mathrm{mmol}), 2$-chloro-1-methylpyridinium iodide (3, $42 \mathrm{mg}$, $0.164 \mathrm{mmol})$, and triethylamine $(17 \mathrm{mg}, 0.164 \mathrm{mmol})$ were dissolved in DCM (20 mL) and allowed to react at room temperature for $24 \mathrm{~h}$. After that, the solution was characterized by ESI to detect the existence of aminosquaraine dye 5'. No peak for 5' was detected (Figure S5). Finally, the mixture was dried by vacuum and ran through column chromatography. No 5' was identified. Part of the starting compound 4' was recovered $(17 \mathrm{mg}$, recovery ratio $=34 \%)$.

Scheme S5. Attempt to synthesize squaraine dye starting from 4',

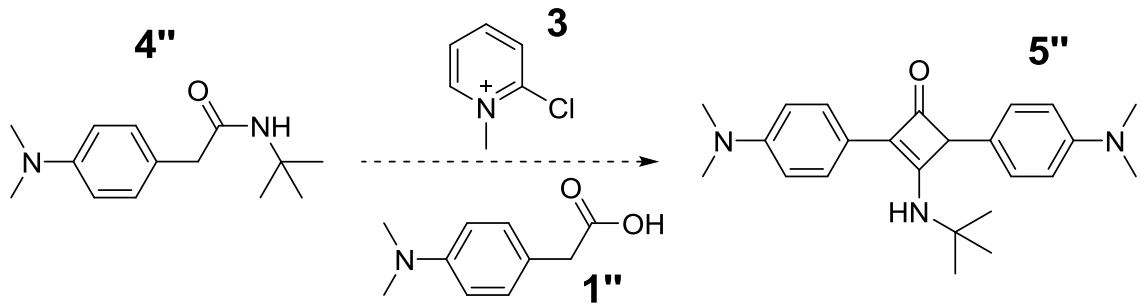

Attempt to synthesize squaraine dye 4"' starting from 4"': Compound 4', (50 mg, $0.214 \mathrm{mmol})$, 4-(dimethylamino)phenylacetic acid (1', $38 \mathrm{mg}, 0.214 \mathrm{mmol})$, 2-chloro-1-methylpyridinium iodide $(3,55 \mathrm{mg}, 0.214 \mathrm{mmol})$, and triethylamine $(21 \mathrm{mg}, 0.214 \mathrm{mmol})$ were dissolved in DCM $(20 \mathrm{~mL})$ and allowed to react at room temperature for $24 \mathrm{~h}$. After that, the solution was characterized by ESI to detect the existence of aminosquaraine dye 5', No peak for 5', was detected (Figure S6). The solution was diluted to $0.1 \mathrm{mM}$ (calculated based on the original concentration of starting amide 4"') and added DDQ (0.2 mM). No long wavelength absorption was detected for the mixture (Figure S7). Finally, the mixture was dried by vacuum and ran through 
column chromatography. No 5"' was identified. Part of the starting compound 4" was recovered $(40 \mathrm{mg}$, recovery ratio $=80 \%)$.

Scheme S6. Oxidation of reduced aminosquaraine dye 5 by DDQ
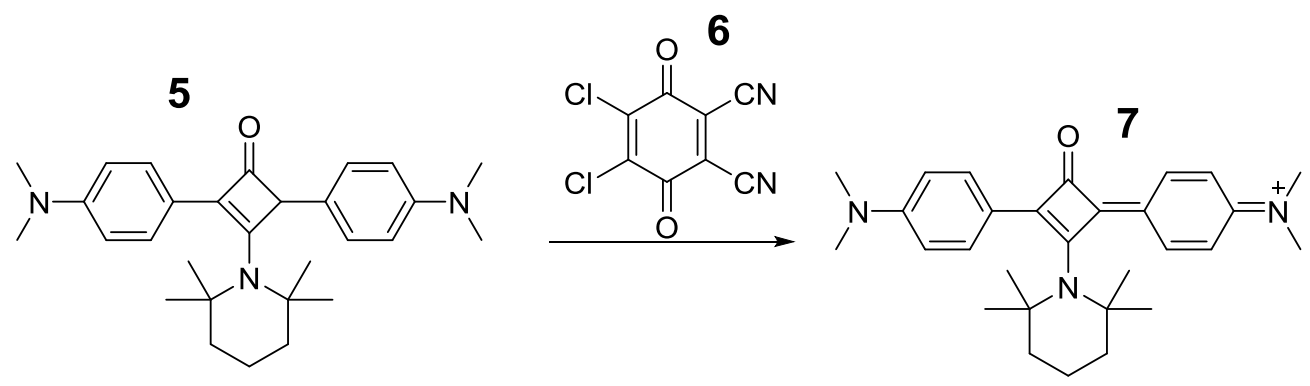

Oxidation of reduced aminosquaraine dye 5 by DDQ: Reduced aminosquaraine dye 5 (6.0 mg, $0.013 \mathrm{mmol})$ was dissolved in deuterated chloroform $(550 \mu \mathrm{L})$. Later, DDQ $(6,3.0 \mathrm{mg}, 0.013$ mmol) was added. Instant color change from light yellow to deep green was observed. The mixture was directly characterized by ${ }^{1} \mathrm{H}$ NMR and ESI to confirm the structure of oxidized species 7. ${ }^{1} \mathrm{H}$ NMR (500 MHz, CDCl 3 ), $\delta 8.41$ (br, 4H, Ph- $\underline{\mathrm{H}}$ ), 6.93 (br, 4H, Ph- $\underline{\mathrm{H}}), 3.67$ (br, 12H, $\left.\underline{\mathrm{H}}_{3}\right), 2.05$ (br, 2H, $-\underline{\mathrm{C}}_{2}$ ), 1.82 (br, 4H, - $\underline{\mathrm{C}}_{2}$ ), 1.46 (br, 12H, - $\underline{\mathrm{C}}_{3}$ ) (Figure S8), ESI-MS (low resolution, positive mode): calculated for $\mathrm{C}_{29} \mathrm{H}_{38} \mathrm{~N}_{3} \mathrm{O}, \mathrm{m} / \mathrm{z}, 444.3[\mathrm{M}]^{+}$; found $444.3[\mathrm{M}]^{+}$. The UV-Vis absorption characterization was also performed and compared with the solution of reactants $\mathbf{5}$ and 6, respectively.

Titration of 5 by DDQ to determine the reaction equivalents: Deuterated chloroform solution of 5 and $\mathbf{6}$ were prepared both in concentration of $0.024 \mathrm{mM}$. Four portions of $\mathbf{6}$ solution (volume of each portion was $125 \mu \mathrm{L}$ ) was added to $500 \mu \mathrm{L}$ solution of $\mathbf{5}$. The ${ }^{1} \mathrm{H}$ NMR spectra was taken after each addition. The quantity ratios of 5 and $\mathbf{7}$ in the mixtures were recorded based on the NMR peaks integral and used for the plotting of titration curve (Figure S9). 